nine of them produced an additional $92 \mathrm{kDa}$ species. Experimental animal studies have demonstrated that production of both species of gelatinase correlates with increased metastatic potential. ${ }^{10}$ Further studies will be required to assess the impact of these findings.

Both human and animal studies into other tumours would suggest that the production of metastases is a very inefficient process and that, although literally millions of cells may be shed by a tumour into the.circulation daily, very few cells have the necessary prerequisites to survive and develop. ${ }^{11}$ It is probable that uveal melanomas are equally inefficient in producing metastases; indeed their unusual pattern of dissemination strongly supports this. Beware the patient with a glass eye and a large liver: this axiom, known to many, serves to remind us of the curious propensity for uveal melanomas to metastasise to the liver. The majority of patients with metastatic uveal melanoma either present with, or subsequently develop, liver deposits. ${ }^{12}{ }^{13}$ Why uveal melanoma cells are hepatophilic is unknown. It cannot merely be a function of simple anatomical accessibility. Circulating tumour cells, once they have left the confines of the eye, must traverse the lungs before reaching the liver, and yet, despite this, pulmonary metastases are relatively uncommon. Presumably the liver provides the necessary environmental conditions for circulating tumour cells to flourish and replicate. The factors which facilitate the tumour's ability to colonise the liver remain elusive.

At present, we have almost no insight into those crucial events which initiate the development of uveal melanomas and the factors which promote their ultimate dissemination.
The acquisition of this knowledge will provide us with more accurate indices of survival and a greater prospect of cure.

IAN RENNIE

Department of Ophthalmology and Orthoptics,

University of Sheffield,

Royal Hallamshire Hospital,

Sheffield S10 2JF

I Shammas H, Blodi F. Prognostic factors in choroidal and ciliary body melanomas. Arch Ophthalmol 1977; 95: 63-9.

2 Seddon JM, Albert DM, Lavin PT, Robinson N. A prognostic factor study of disease-free interval and survival following enucleation for uveal melanoma. Arch Ophthalmol 1983; 101: 1894-9.

3 Deiner-West M, Hawkins BS, Markowitz JA, Schachat AP. A review of mortality from choroidal melanoma: II. A meta-analysis of 5-year mortality rates following enucleation, 1966 through 1988 . Arch Ophthalmol 1992;110. 245-50.

4 Zimmerman LE, Mclean IW, Foster WD. Does enucleation of the eye containing a malignant melanoma prevent or accelerate the dissemination of containing a malignant melanoma prevent or accel

5 Fidler IF. Critical factors in the biology of human cancer metastasis: twentyeighth GHA Clowes memorial award lecture. Cancer Res 1990; 50: 6130-8.

6 Sisley K, Rennie IG, Cottam DW, Potter AM, Potter CW, Rees RC Cytogenetic findings in six posterior uveal melanomas. Genes Chrom Cancer 1990; 2: 205-9.

7 Prescher G, Bornfeld N, Becher R. Nonrandom chromosomal abnormalities in primary uveal melanoma. F Natl Cancer Inst 1990; 82: 1765-9.

8 Sisley K, Cottam DC, Rennie IG, Parsons MA, Potter AM, Potter CW, et al. Non-random abnormalities of chromosomes 3,6 , and 8 associated with posterior uveal melanoma. Genes Chrom Cancer 1992; 5: 197-200.

9 Cottam DW, Rennie IG, Woods K, Parsons MA, Bunning RAD, Rees RC. Gelatinolytic metalloproteinase secretion patterns in ocular melanoma. Invest Ophthalmol Vis Sci 1992; 33.

10 Cottam DW, Rees RC. Regulation of matrix metalloproteinases: their role in tumor invasion and metastasis. Int $\mathcal{F}$ Oncol 1993; 2: 861-72.

11 Butler TP, Gullino PM. Quantitation of cell shedding into efferent blood of mammary adenocarcinoma. Cancer Res 1975; 35: 512-6.

12 Jenson OA. Malignant melanomas of the uvea: a recent follow up of cases in Denmark, 1943-1952. Acta Ophthalmol 1970; 48: 1113-28.

13 Einhorn LH, Burgess MA, Gottleib JA. Metastatic patterns of choroidal melanoma. Cancer 1974; 34: 1001-4.

\title{
Macrophages in the pathobiology of epiretinal membranes: multifunctional cells for a multistage process
}

Epiretinal membranes are proliferations at the vitreoretinal junction and frequently cause traction retinal detachment by virtue of scar-like contraction. Contractile epiretinal membranes typically arise as a complication of proliferative diabetic retinopathy (PDR) or rhegmatogenous retinal detachment. Post-detachment membranes form part of the spectrum of proliferative vitreoretinopathy (PVR). PVR membranes essentially are avascular and have a fibrocellular histological appearance, whereas PDR membranes characteristically are fibrovascular in composition. Nevertheless, both fibrovascular and fibrocellular membranes contain a variety of non-vascular cell types including retinal glia (astrocytes and Müller cells), retinal pigment epithelial cells, and inflammatory cells.

Inflammatory cells have long been recognised as a component of epiretinal membranes. ${ }^{1}$ However, epiretinal inflammatory cells have received relatively little attention while much research effort has concentrated on the contribution of non-inflammatory cells like retinal pigment epithelial cells. Indeed, there is evidence that dedifferentiated retinal pigment epithelial cells contribute to some of the macrophage-like cells present in epiretinal membranes. ${ }^{2}$ However, PDR and PVR membranes also contain cells with the locomotory characteristics of the mononuclear phagocyte system (MPS), ${ }^{3}$ and MPS macrophages may be detected in PVR membranes using immunohistochemical methods. ${ }^{4}$

The introduction of immunohistochemical and tissue culture techniques into the study of epiretinal membranes has marked a shift in the emphasis of research towards the functions, rather than the origins, of cells in the membranes. It is believed that macrophages are involved in both the initiation and the subsequent development of epiretinal membranes. Thus macrophage injections into the vitreous can provoke experimental epiretinal membrane formation. Moreover, epiretinal membrane formation is a multistage process which is likened to wound repair mechanisms elsewhere in the body, a process which is critically dependent upon the multiple activities of macrophages. ${ }^{6}$ Apart from their phagocytic functions, macrophages in repair processes are capable of producing a range of enzymes which degrade tissue components. ${ }^{6}$ Other macrophage products involved in wound healing include chemotactic agents (for example, the fibronectins), mitogens (such as peptides of the fibroblast growth factor family), and factors which promote extracellular matrix synthesis (for example, peptides of the transforming growth factor $B$ family).

Variations in macrophage behaviour are reflected by alterations within a group of antigens expressed by the cells. Two such macrophage activity related antigens are recognised by the monoclonal antibodies 27E10 and RM3/1 respectively. ${ }^{78}$ The antigen detected by $27 \mathrm{E} 10$ is displayed by macrophages during the early, inflammatory stages of healing wounds but not during the late, fibrosing phases. By contrast, RM3/1 is expressed by macrophages during the late rather than the early phases of wound repair. Although the precise functional significance of the antigens identified by $27 \mathrm{E} 10$ 
and $\mathrm{RM} 3 / 1$ is yet to be resolved, the implication is that $27 \mathrm{E} 10+$ macrophages are involved in the events of early wound repair (when active cell recruitment and proliferation is taking place in response to locally produced motogens and mitogens) while $R M 3 / 1+$ macrophages are involved in late stage events (a phase when collagen production and remodelling are occurring)..$^{78}$

In this issue, Esser and colleagues report the findings of their study concerning 27E10+ and RM3/1+ macrophage subsets in epiretinal membranes. Idiopathic epimacular membranes and membranes from patients with PVR following conventional detachment procedures were devoid of $27 \mathrm{E} 10+$ macrophages and only a few of these membranes contained occasional RM3/1+ macrophages. By contrast, both types of macrophage were observed in most PDR membranes as well as in some post-traumatic (surgical or accidental) PVR membranes of less than 9 months' clinical duration. The results of Esser and coworkers suggest that post-traumatic PVR and PDR epiretinal membranes have a more protracted course than do non-traumatic PVR and idiopathic macular pucker membranes. Furthermore, the findings of the investigation intimate that there is no clear delimitation between early, inflammatory phase events and late stage fibrosis in the formation of many epiretinal membranes.
Esser and colleagues conclude that epiretinal proliferation may be inhibited by the early use of steroids. Indeed, there is hope that other therapeutic agents will be revealed as we expand our understanding of the pathobiology of PVR and PDR.

PAUL HISCOTT

Unit of Ophthalmology,

Department of Medicine,

University of Liverpool,

PO Box 147

Liverpool L69 3BX

1. Parsons JH. The pathology of the eye. Vol 2. London: Hodder and Stoughton, 1905: 542-600.

2 Mueller-Jensen K, Machemer R, Azarnia R. Autotransplantation of retinal pigment epithelial cells in intravitreal diffusion chamber. Am f Ophthalmol 1975; 80: 530-7

3 Hiscott PS, Grierson I, Hitchins CA, Rahi AHS, McLeod D. Epiretinal membranes in vitro. Trans Ophthalmol Soc UK 1983; 103: 89-102.

4 Weller M, Heimann $K$, Wiedemann P. Immunochemical studies of epiretinal membranes using APAAP complexes: evidence for macrophage involvement in traumatic proliferative vitreoretinopathy. Int Ophthalmol 1988; 11: 181-6.

5 Hui YN, Sorgente N, Ryan SJ. Posterior vitreous separation and retinal detachment induced by macrophages. Graefes Arch Clin Exp Ophthalmol 1987; 225: 279-84.

6 Peacock EE. Wound repair. 3rd ed. Philadelphia: Saunders, 1984.

7 Zwadlo G, Schlegel R, Sorg C. A monoclonal antibody to a subset of human monocytes found only in the peripheral blood and inflammatory tissues. F Immunol 1986; 137: 512-8.

8 Zwadlo G, Voegli R, Osthoff KS, Sorg C. A monoclonal antibody to a novel differentiation antigen on human macrophages associated with the down regulatory phase of the inflammatory process. Exp Cell Biol 1987; 55: 295-304. 